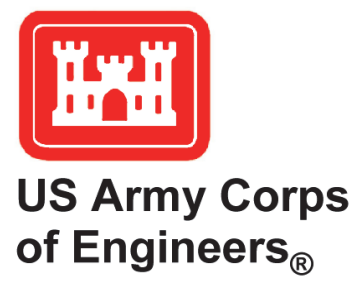

\section{Shoreline Change Modeling Using One-Line Models: Application and Comparison of GenCade, Unibest, and Litpack}

by Kimberly E. Townsend, Robert C. Thomas, and Ashley E. Frey

PURPOSE: The purpose of this Coastal and Hydraulics Engineering Technical Note (CHETN) is to demonstrate application of three popular and readily available shoreline change models employing the one-line approach (GenCade, Unibest CL+, and Litpack).

INTRODUCTION: This CHETN is the final report in a two-part desktop study to compare oneline shoreline change models. Thomas and Frey (2013), the first report in this series, documented the differences and similarities in the most popular and available shoreline change models employing the one-line approach. This report will demonstrate application of three popular models discussed in Thomas and Frey (2013). To demonstrate application of those models, a series of simple, idealized cases was run with Unibest CL+ 7.1 (Deltares 2011), Litpack within the Mike Zero 2011 software package (Delft Hydraulic Institute (DHI) 2009), and GenCade 1.0 (Frey et al. 2012). The standard benchmark cases tested were developed and originally presented in Frey et al. (2012) and are separated into the primary coastal structures and components that are frequently applied in GenCade. A detailed description of capabilities and limitations of each model is presented in Thomas and Frey (2013).

The primary modeler had no prior shoreline change modeling experience at the beginning of this exercise. A new user was selected for this evaluation to compare user interfaces, model documentation, and general ease of model use. The user's conclusions are presented at the end of this CHETN. Model documentation used during this study is listed in the references.

EVALUATED BENCHMARK CASES: The category of idealized model domains developed for the standardized benchmark cases was the straight shoreline. The purpose of the straight shoreline domain is to provide an uncomplicated foundation to test the most fundamental processes and the impact of coastal structures within Unibest, Litpack, and GenCade. The cases tested include the following:

- Case 1. Straight shoreline, no structures

- Case 2. Straight shoreline, single groin

- Case 3. Straight shoreline, detached breakwater

- Case 4. Straight shoreline, T-groin

- Case 5. Straight shoreline, seawall

- Case 6. Straight shoreline, beach fill 


\section{Report Documentation Page}

Form Approved

OMB No. 0704-0188

Public reporting burden for the collection of information is estimated to average 1 hour per response, including the time for reviewing instructions, searching existing data sources, gathering and maintaining the data needed, and completing and reviewing the collection of information. Send comments regarding this burden estimate or any other aspect of this collection of information,

including suggestions for reducing this burden, to Washington Headquarters Services, Directorate for Information Operations and Reports, 1215 Jefferson Davis Highway, Suite 1204, Arlington

VA 22202-4302. Respondents should be aware that notwithstanding any other provision of law, no person shall be subject to a penalty for failing to comply with a collection of information if it

does not display a currently valid OMB control number.

1. REPORT DATE

SEP 2014
2. REPORT TYPE
3. DATES COVERED

00-00-2014 to 00-00-2014

4. TITLE AND SUBTITLE

Shoreline Change Modeling Using One-Line Models: Application and Comparison of GenCade, Unibest, and Litpack

6. AUTHOR(S)

7. PERFORMING ORGANIZATION NAME(S) AND ADDRESS(ES)

U.S. Army Engineer Research and Development

Center,Vicksburg,,MS,39180

9. SPONSORING/MONITORING AGENCY NAME(S) AND ADDRESS(ES)

10. SPONSOR/MONITOR'S ACRONYM(S)

11. SPONSOR/MONITOR'S REPORT

$\operatorname{NUMBER}(\mathrm{S})$

12. DISTRIBUTION/AVAILABILITY STATEMENT

Approved for public release; distribution unlimited

13. SUPPLEMENTARY NOTES

14. ABSTRACT

15. SUBJECT TERMS

16. SECURITY CLASSIFICATION OF:

a. REPORT

unclassified b. ABSTRACT

unclassified c. THIS PAGE

unclassified
17. LIMITATION OF ABSTRACT

Same as

Report (SAR)
18. NUMBER 19a. NAME OF

OF PAGES RESPONSIBLE PERSON

13 
Table 1 lists common parameters and forcing applied for each case. Model-specific parameters were varied to enable comparison.

\begin{tabular}{||l|l||}
\hline \multicolumn{2}{|l||}{ Table 1. Parameters for all benchmark cases. } \\
\hline \hline Parameter & Value \\
\hline \hline Starting shoreline position & 100 meters $(\mathrm{m})$ from and parallel to the grid \\
\hline Offshore wave height & $0.75 \mathrm{~m}$ \\
\hline Period & $8 \mathrm{~seconds}$ \\
\hline Wave angle & $+15^{\circ}$ \\
\hline Mean grain size diameter & 0.25 millimeter $(\mathrm{mm})$ \\
\hline Active beach height & $11 \mathrm{~m}(1 \mathrm{~m}$ berm height $+10 \mathrm{~m}$ depth of closure $)$ \\
\hline Simulation period & 2 years $(\mathrm{yr})$ \\
\hline
\end{tabular}

MODEL RESULTS: This section discusses the results for each model and case. Figures showing mean net transport and final shoreline position at the end of the simulation period are included for most cases.

Case 1: Straight Shoreline, No Structures. The simplest case of a straight shoreline without coastal structures was tested first. As expected, there is zero shoreline change since the alongshore gradients in transport are zero, and transport is constant at approximately 200,000 cubic meters $\left(\mathrm{m}^{3}\right) / \mathrm{yr}$ in all three models. The transport rate was calculated in GenCade with many of the default parameters; in order to compare the models for each case, the parameters in Unibest and Litpack were adjusted to produce a transport rate of $200,000 \mathrm{~m}^{3} / \mathrm{yr}$.

Case 2: Straight Shoreline, Single Groin. A case having a straight shoreline with a single groin $75 \mathrm{~m}$ long (175 $\mathrm{m}$ from the grid origin) at the center of the domain was tested next (Figures 1 and 2). The groin presents an obstruction to longshore transport, which results in reduced transport rates as sediment is bypassed around the groin. This local transport reduction in the vicinity of the groin translates to a gradient in transport rates as transport transitions to and from background rates, which drives accretion of sediment and resulting shoreline progradation seaward on the left side of the groin as the transport rates decrease significantly at the groin.

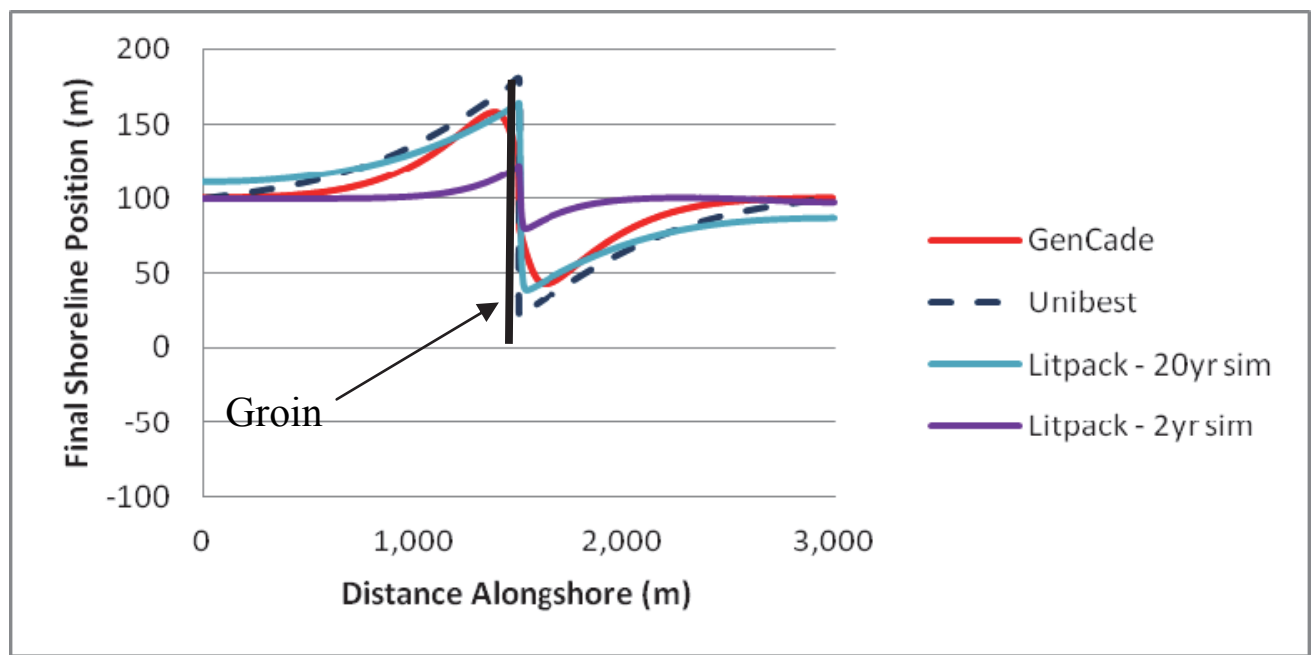

Figure 1. Calculated shoreline position for a straight shoreline with a single groin. 


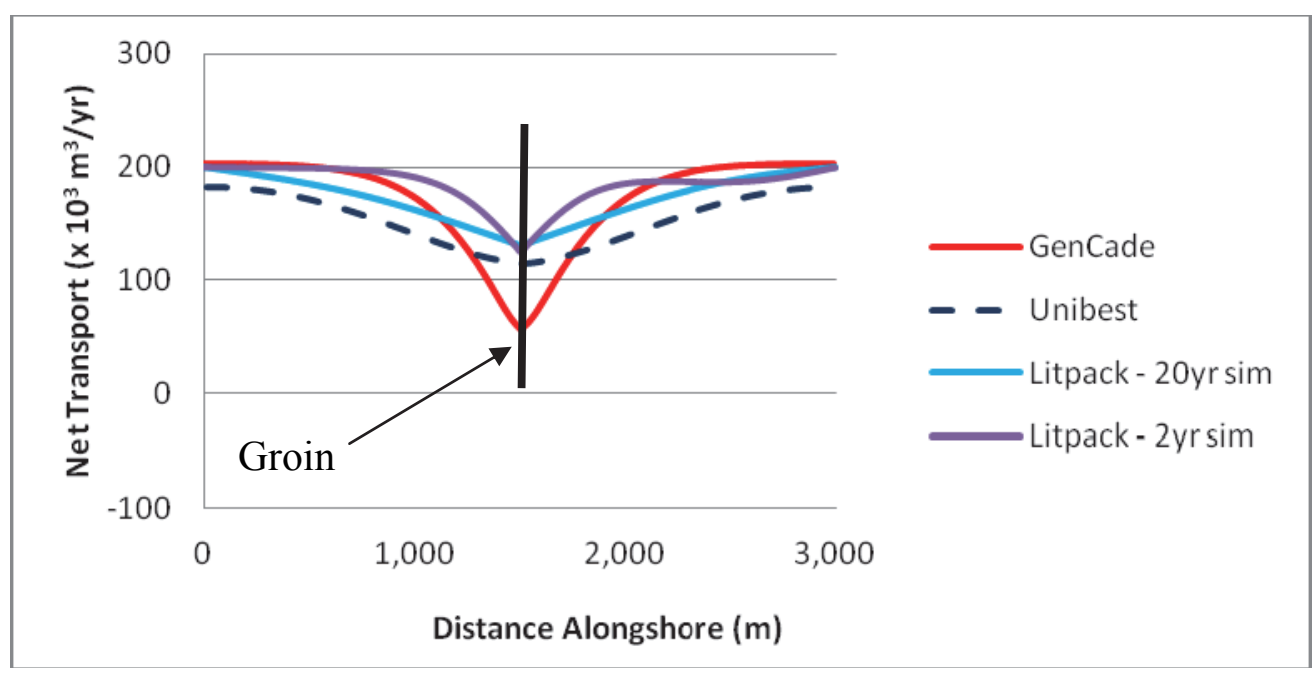

Figure 2. Calculated net transport for a straight shoreline with a single groin.

There was good agreement between GenCade results and Unibest results for the simulation with a single groin. However, when the scenario was tested in Litpack, it was found that a longer simulation time of $20 \mathrm{yr}$ was needed to produce similar results. When the Litpack model was run for only $2 \mathrm{yr}$, the change in shoreline position across the length of the beach was much more modest. Because of the constant angle boundary condition in Litpack (the only option), running the scenario for $20 \mathrm{yr}$ resulted in substantially greater volume change than the other models. Varying the length of the groin was also tested, although it resulted in no significant improvement. The longer run with Litpack was only undertaken as an exercise to understand Litpack model behavior for a case that does not appear to accurately reflect physical processes; therefore, the other models were not run for the longer period.

Case 3: Straight Shoreline, Detached Breakwater. A detached breakwater case was evaluated with a $90 \mathrm{~m}$-long emergent breakwater at the center of the domain located $100 \mathrm{~m}$ offshore of the shoreline (200 m from the origin) at a depth of $6 \mathrm{~m}$ (Figures 3 and 4). Because of the breakwater, the transport rate decreases directly behind the structure. In GenCade, the net transport decreases from approximately $200,000 \mathrm{~m}^{3} / \mathrm{yr}$ to approximately $25,000 \mathrm{~m}^{3} / \mathrm{yr}$ directly behind the structure. Litpack had very similar results. Unibest, conversely, produced much more subtle changes in transport rate and in shoreline position. This is because there is no separate wave model to account for diffraction in Unibest. To approximate this process, the transport rate behind the breakwater was estimated using smaller waves, but was not rigorously refined. Therefore, the results shown for Unibest would not be expected to be representative. As discussed in Thomas and Frey (2013), Unibest does have a method for modeling breakwaters, but that method was not applied here since a separate wave model was not developed for this model comparison.

Case 4: Straight Shoreline, T-groin. A T-groin case was demonstrated with a 90 m-long Thead groin at the center of the domain located $100 \mathrm{~m}$ offshore of the shoreline with all diffracting groin tips set to a depth of $6 \mathrm{~m}$. Figures 5 and 6 show a nearly symmetric shoreline change response in the lee of the T-groin and on either side of the groin and the accretion of shoreline out to the structure tip. The transport rates decrease from a background rate to zero directly adjacent to the groin structure. There was good agreement between GenCade results and Litpack results over 
the entire length of the domain. However, as in Case 3, Unibest did not return similar results because a separate wave model was not run to calculate the diffraction of waves resulting from the breakwater section of the T-groin.

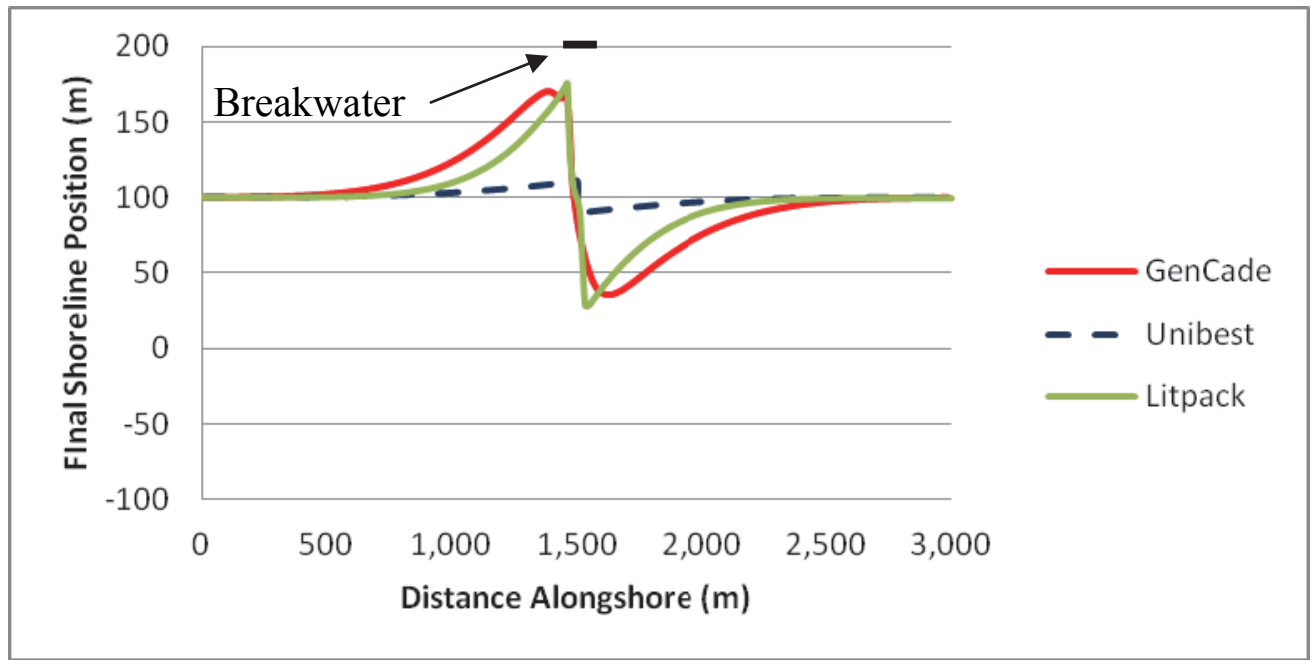

Figure 3. Calculated shoreline position for a straight shoreline with a breakwater.

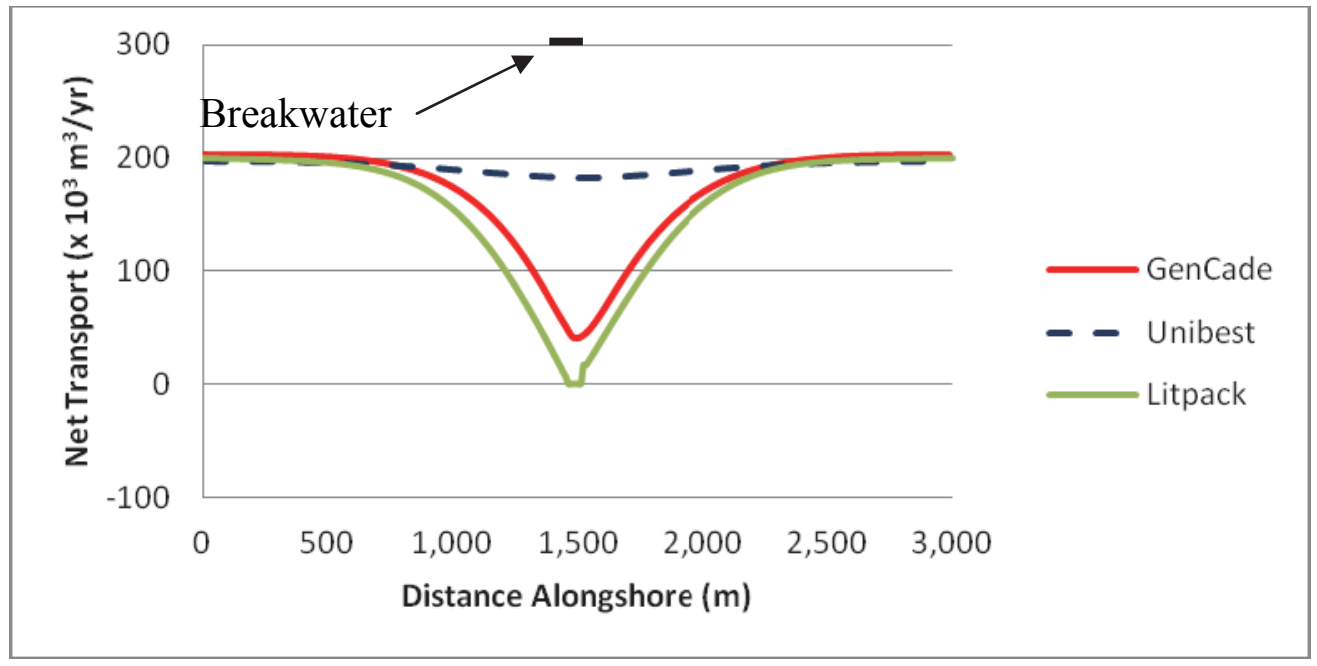

Figure 4. Calculated net transport for a straight shoreline with a breakwater. 


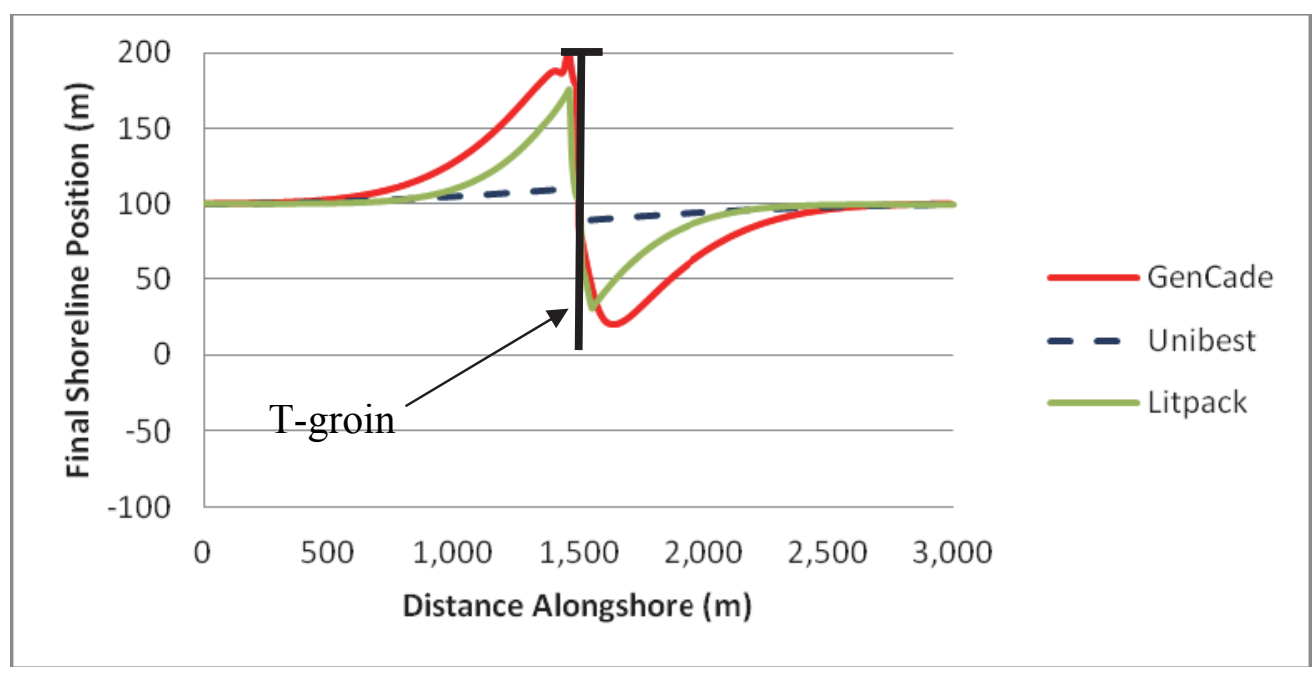

Figure 5. Calculated shoreline position for a straight shoreline with a T-groin.

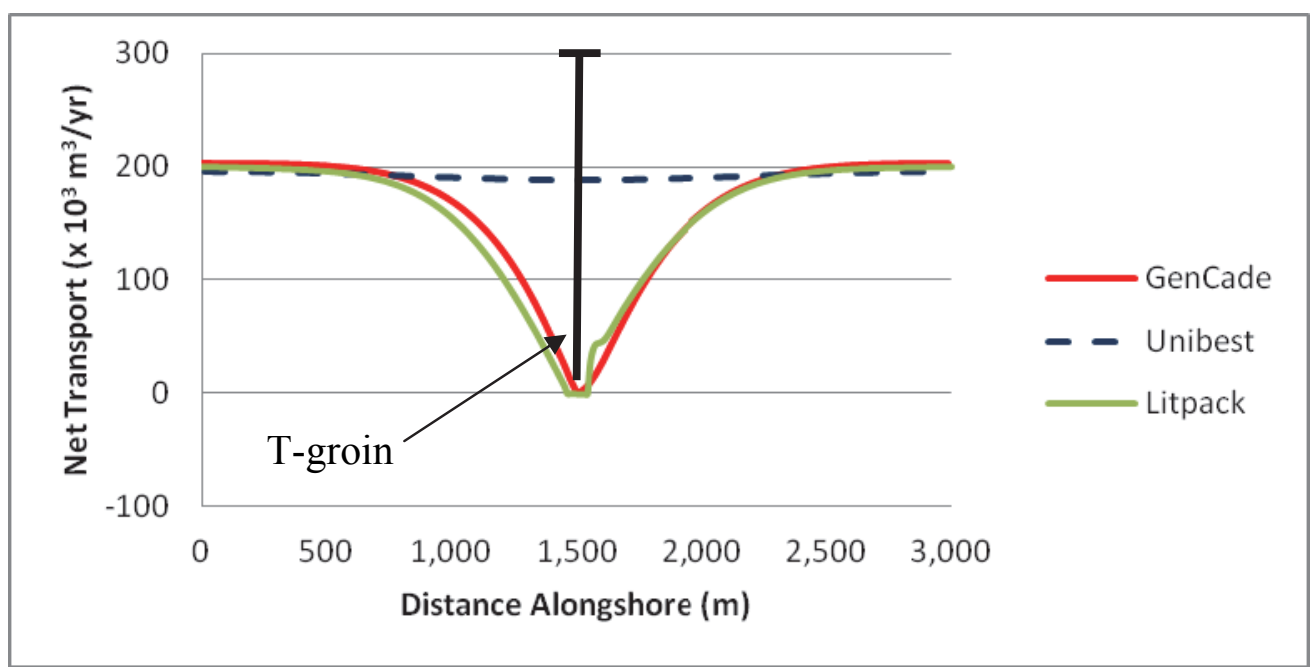

Figure 6. Calculated net transport for a straight shoreline with a T-groin.

Case 5: Straight Shoreline, Seawall. A seawall case was demonstrated with a $100 \mathrm{~m}-1$ long seawall at the center of the domain located $10 \mathrm{~m}$ shoreward of (behind) the shoreline. Since a seawall that lies behind a straight shoreline with no other structures will never become exposed, a groin was added $100 \mathrm{~m}$ updrift of the seawall to force shoreline erosion in the vicinity of the seawall and expose the seawall to influence downdrift shoreline evolution. The groin is of the same dimensions as that in the single groin case.

Figure 7 shows the shoreline eroding to the right of the groin, exposing the seawall. The seawall halts erosion but accelerates erosion to the right (downdrift) of the seawall. All three models show some accretion in front of the seawall over the representative period. Overall, there was general agreement between GenCade, Unibest, and Litpack for this case with substantial differences in magnitude of updrift accretion and downdrift erosion in Litpack, as discussed under the single groin case. 


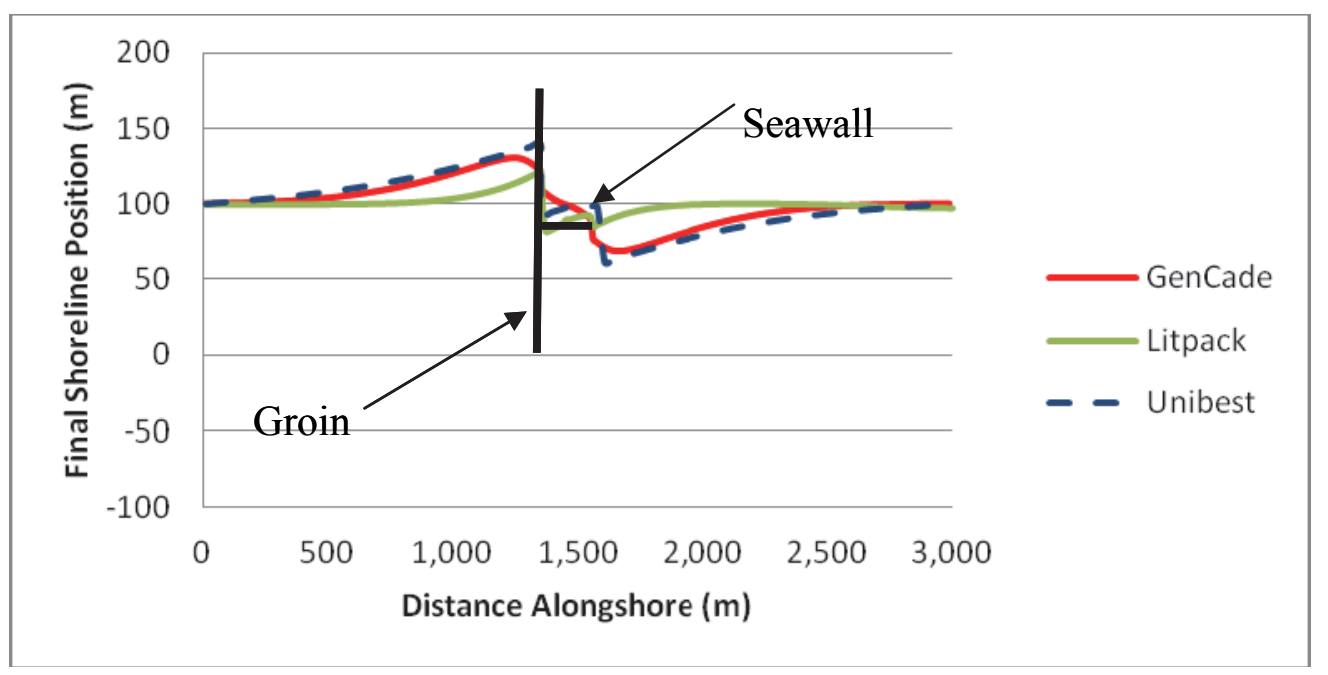

Figure 7. Calculated shoreline position for a straight shoreline with a seawall.

Case 6: Straight Shoreline, Beach Fill. In GenCade, the case of a straight shoreline without any coastal structures was again tested, but in this case, a beach fill was added to evaluate shoreline progradation during the fill and the diffusion of the material and shoreline evolution after project completion (Figures 8 and 9). In GenCade, the beach fill project was initiated 2 months into the simulation and involved a construction duration of 2 months adding $50 \mathrm{~m}$ of berm width over an alongshore distance of $500 \mathrm{~m}$. Upon beach fill completion (i.e., after two months of pumping fill onto the berm), no additional material was added.

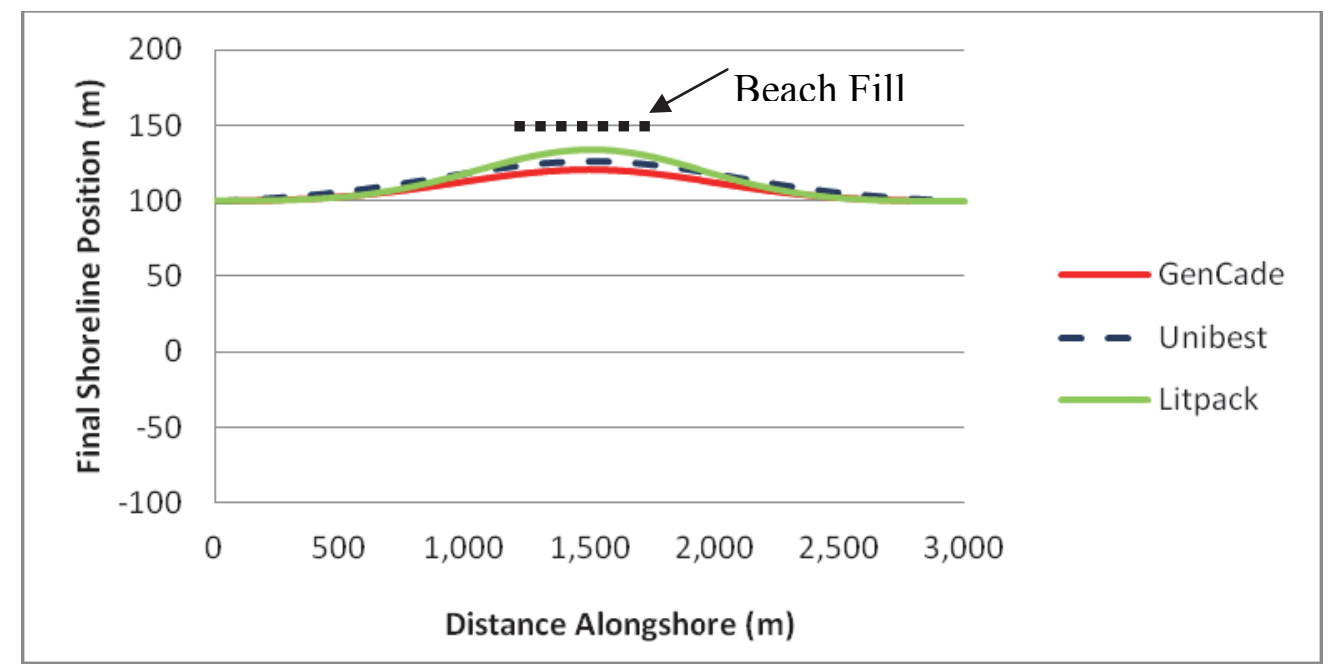

Figure 8. Calculated shoreline position for a straight shoreline with beach fill/shoreline advance. 


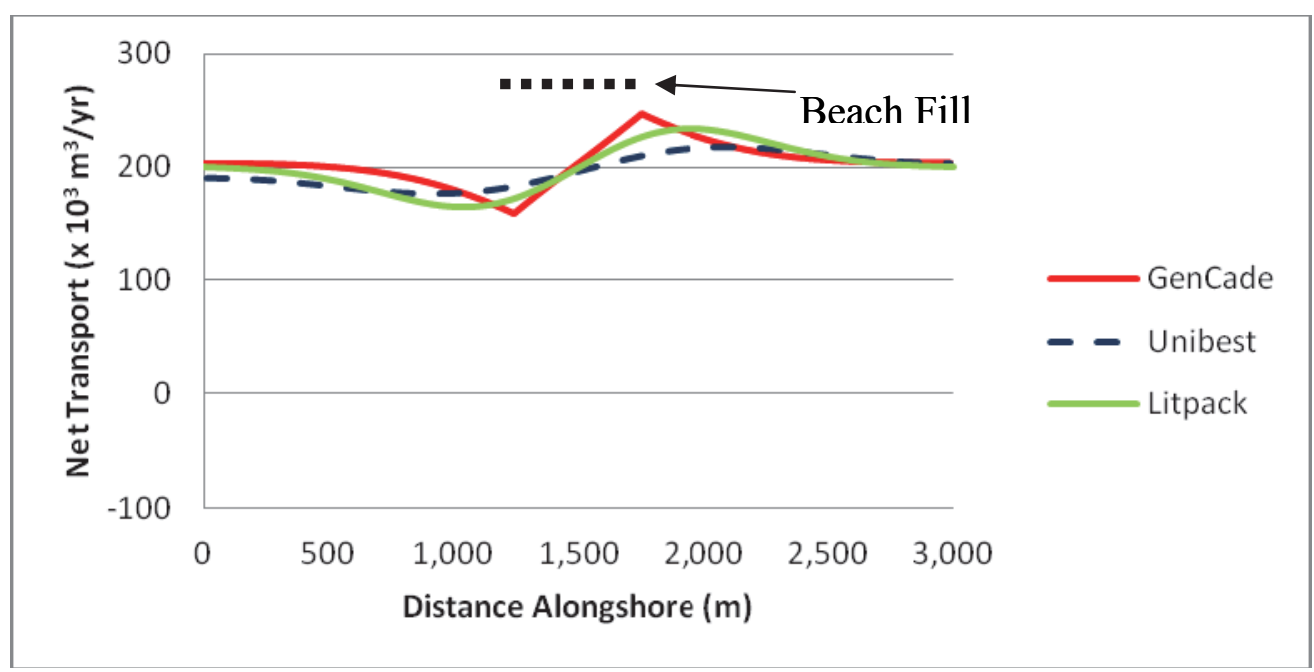

Figure 9. Calculated net transport for a straight shoreline with a beach fill/shoreline advance.

In Unibest, however, the *.tab file, which contains the nourishment volumes in time, could not be read, perhaps due to a version issue, so nourishment could not be tested. Instead, a shoreline advance was added and modeled. This method was employed in Litpack, as well. All three model results clearly show the lateral diffusion of the beach fill material along the shoreline. It is also evident that the greatest deviation from background transport rate occurs at the fill transition zones. There was visible accretion to the left and right of the shoreline advance, with erosion happening at the site of the shoreline advance.

USER EXPERIENCE: This section discusses the graphical user interfaces (GUI) of Unibest and Litpack and the basic concepts of operating each. Some representative screens shots from each GUI are included. The GenCade GUI is described in detail in Frey et al. (2012).

Unibest CL+. Unibest CL+ consists of two integrated sub-modules: the longshore transport module (LT-module) and the coastline module (CL-module). Longshore sediment transport is computed with the LT-module separately for a number of cross-shore profiles along a coastline. These transport calculations are then used in the CL-module to perform coastline evolution simulations in which the effects of structures such as groins, offshore breakwaters, and revetments can be incorporated. In Unibest, the layout of the GUI includes a tree view (Figure 10) so it is clear to the user which files are being used within a certain project. Unibest also contains a visualization area to set up a model. In the CL-module it is possible to edit files, including structures, through pop-up dialogs.

In Unibest, the administration of the CL-module is also facilitated through a pop-up dialog in which the file administration and model run settings can be specified, such as the time frame of the simulation and output/numerical time-step. The CL-module is run from the CL run menu (Figure 11). Here, it is possible to present an erosion graph, which is a visualization of the coastline erosion/accretion along the coastline, or make an animation. 


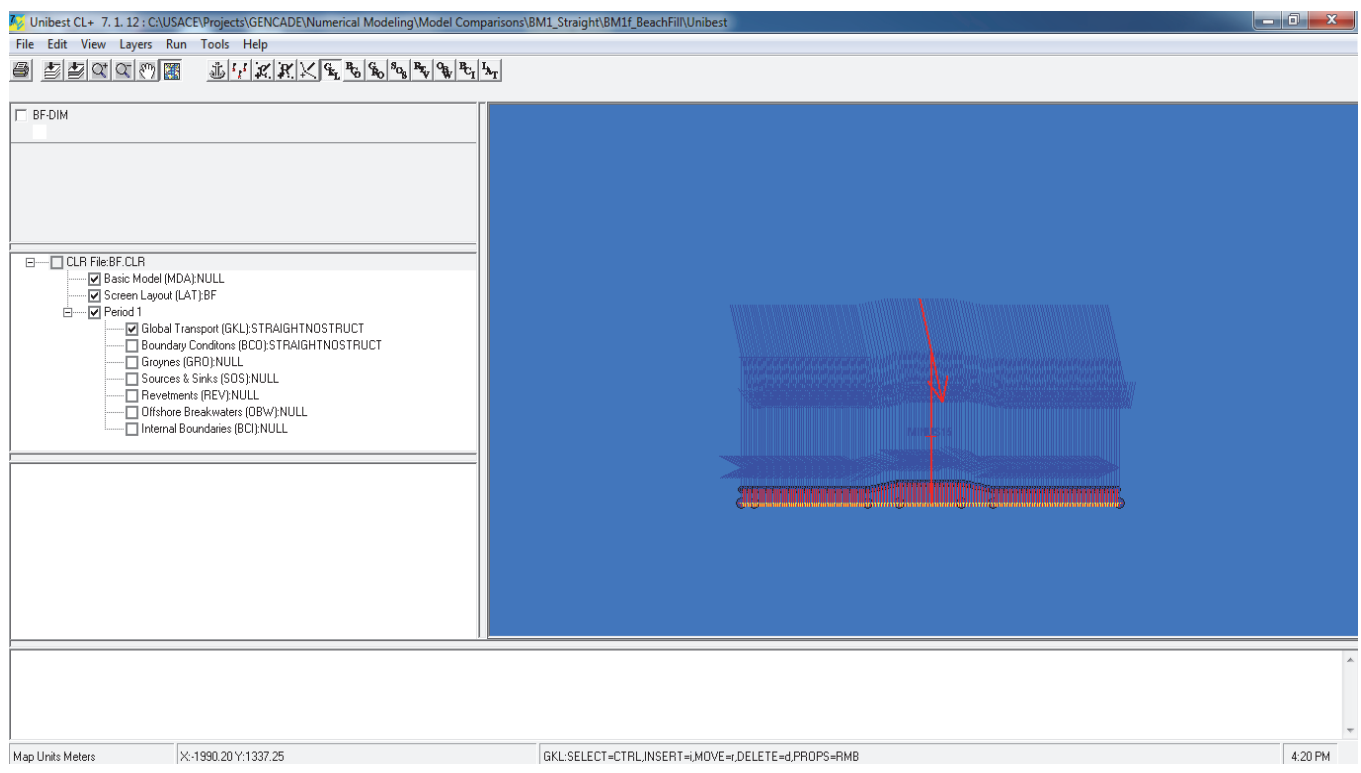

Figure 10. Unibest GUI showing the model tree explorer (left) and model domain (right).

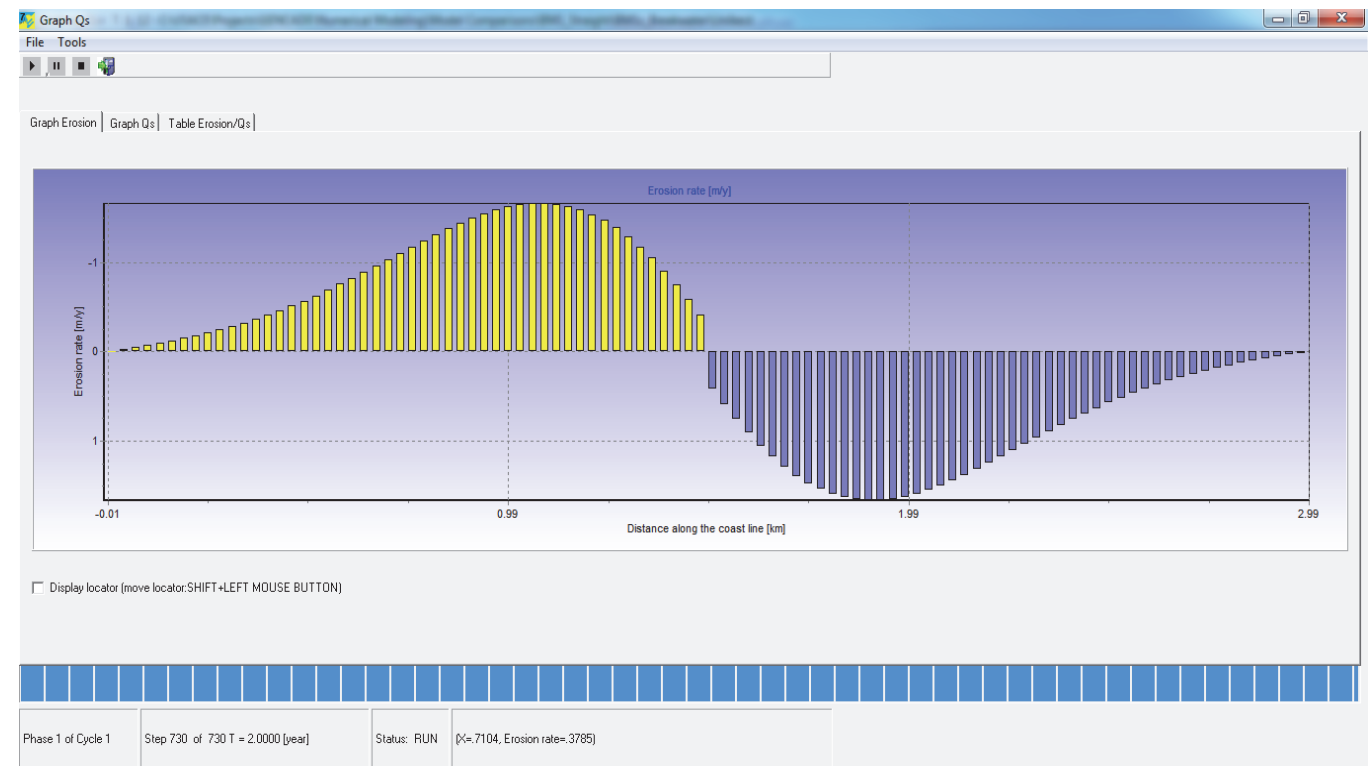

Figure 11. CL Run Menu in Unibest.

Litpack. Litpack's menu system is more interactive compared to that of Unibest in terms of model documentation and Help. At each stage within the menu tree in Litpack, relevant Help menu screens are offered to provide guidance. A convenient feature of Litpack is the copy-andpaste option for direct import and export from spreadsheet programs. The user also has the option of defining the layout of graphical views, such as font settings, lines, and colors.

A primary feature of Litpack is the integrated modular structure to add on coastline, cross-shore, and backfilling modules. The primary module used for the purposes of this report was Litline, which calculates coastline evolution. To create a new Litpack model setup, the working area 
must be defined by the minimum and maximum coordinates in a rectangular coordinate system. The baseline is defined as a straight line with a certain orientation and a specific number of equidistant grid steps. This line corresponds to the baseline in the Litline module, on which the coastline specifications are based. Figure 12 below shows the graphical setup for a 3,000 m shoreline. The project explorer is shown on the right. The project explorer shows files associated with different models and folders but is not related to model setup in the same way as Unibest.

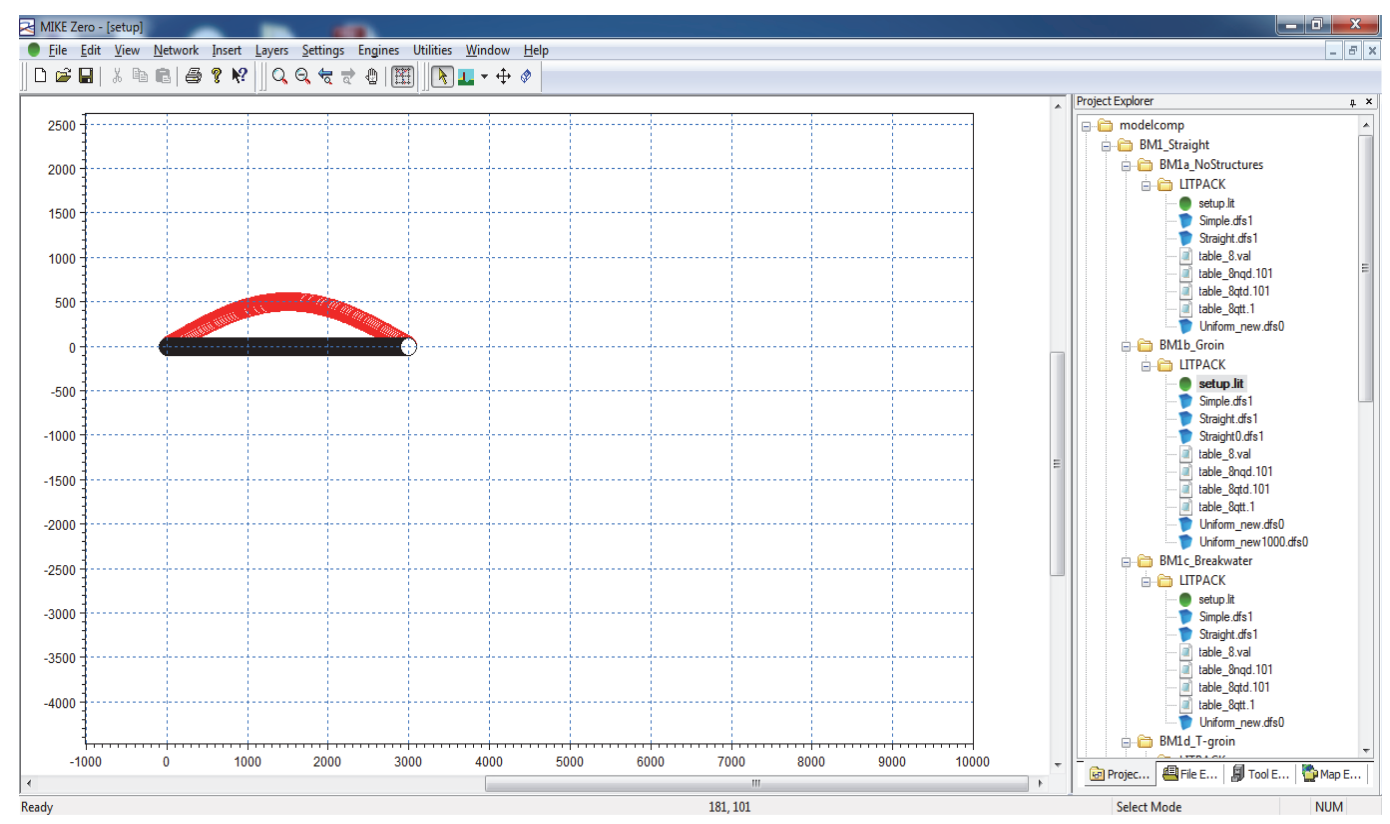

Figure 12. Litpack window shell for $3000 \mathrm{~m}$ shoreline.

Inserting structures in Litpack can be done several different ways: by using the Insert button in the header bar, the icons in the scroll down menu, or the Litline setup dialogs.

Creating a new Litline model setup requires specification of all model parameters, including cross-shore profile properties, coastline properties, wave climate, and sediment transport. Structures can also be added here, as discussed previously. After all the input files are specified, the final Overview dialog provides a summary of setup just created and allows the user to continue with the execution of the program or go back and make changes. When Execute is selected, the user can save the model setup by a filename in a pop-up dialog.

GenCade. GenCade is set up and run from the Surface-Water Modeling System (SMS) graphical user interface. The system allows for easy addition of aerial photos, shorelines, wave data, and one-dimensional grid in the same workspace. This makes model grid creation easier than Unibest or Litpack. Model grids and solution files are shown in the explorer tree on the left of the GUI (Figure 13). An important distinction between GenCade and Unibest is that the explorer tree in SMS does not include model setup parameters.

Setting up model parameters and running the model is completed through windows accessed from the GenCade button on the top of the GUI (Figure 14). One drawback to this approach is that the user must have the appropriate grid type selected before the GenCade model interface will become visible. Although not technically daunting, this limitation can be frustrating for new users. 
Available parameters are discussed in Thomas and Frey (2013); they are generally similar for all three models with differences based on the model capabilities already discussed.

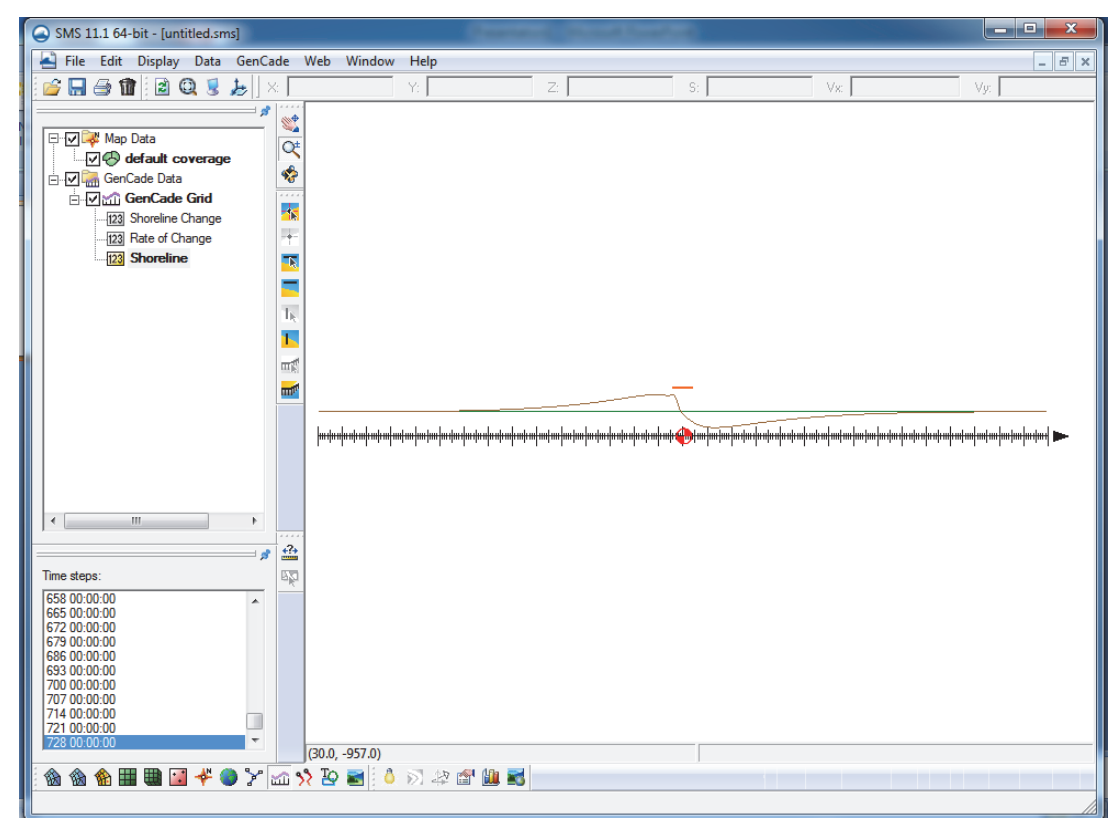

Figure 13. GenCade grid in the SMS GUI.

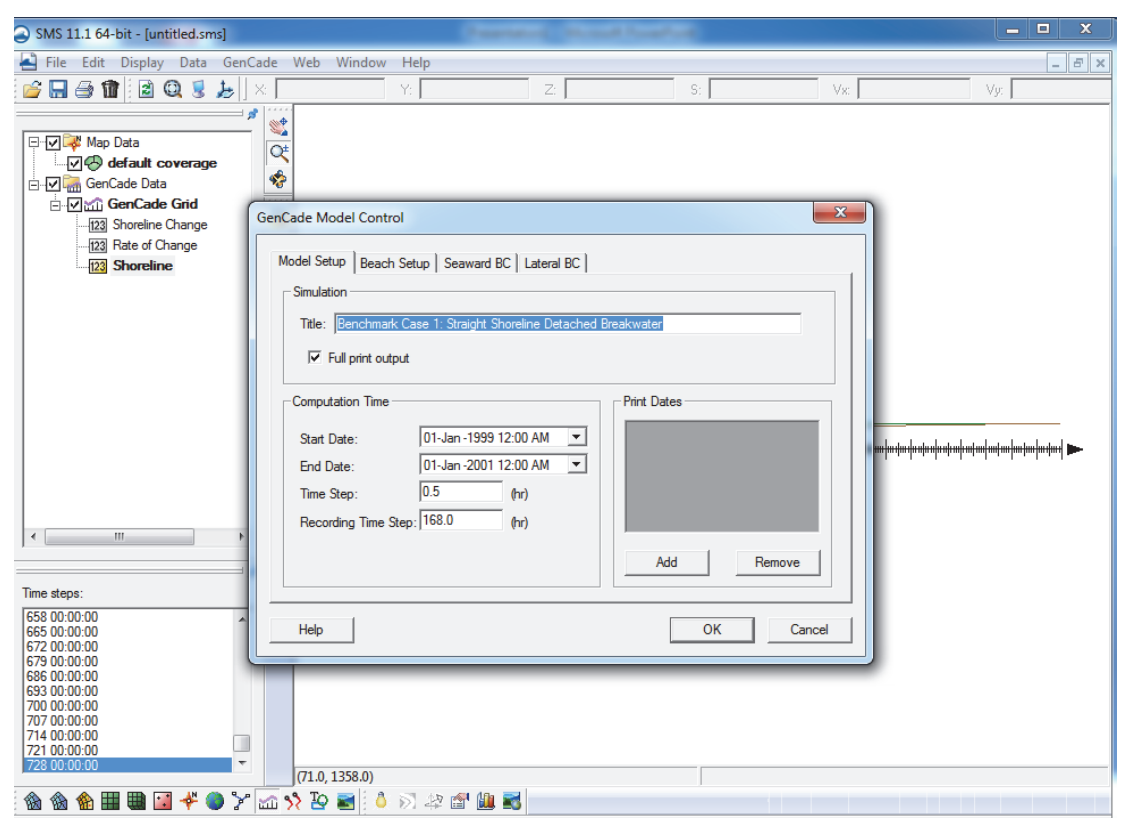

Figure 14. GenCade model control window in the SMS GUI.

CONCLUSIONS: This CHETN documents application of three shoreline change models to a set of standard benchmark cases by a new shoreline change model user. Some general conclusions are summarized as follows:

- Notable differences between models run during this application: 
- Simulating groins on a straight beach was similar in GenCade and Unibest, but Litpack showed substantially less impoundment for the same conditions.

- In GenCade, breakwaters take significantly longer to model than any other feature, primarily because the calculation is intensive, and the model runs in the time domain. Unibest and Litpack both take a frequency domain approach to simulations, significantly reducing simulation time.

- GenCade and Litpack have internal models of wave diffraction, while Unibest does not.

- To take into account wave diffraction around a groin or another structure in Unibest, it is required that the user compute the diffracted waves at several alongshore points in the affected area, either with a suitable wave propagation model or with engineering rules/diagrams. Since this desktop evaluation did not include separate wave modeling, the Unibest results for those cases were not comparative.

- GenCade has an inlet bypassing capability and an inlet reservoir model for calculation of shoal and inlet feature sediment balance, which Unibest and Litpack do not. Therefore, an inlet case was not tested.

- GenCade allows for user-specified beach placement starting after the simulation start time. In both Litpack and Unibest, beach fill is added to the initial shoreline position for analysis. The results were very similar.

- Unibest and Litpack both allow more rigorous approaches to calculating longshore transport. The methods calculate sediment transport at specified profiles across shore. Then the longshore transport is estimated by integrating transport across the profile.

- Although the additional detail possible with the advanced method may provide improved accuracy, populating the needed parameters and evaluating the quality of the results may be problematic with typically existing data (i.e., shoreline position).

- Litpack and Unibest allow users to input numerous grain sizes across the full model domain, rather than being limited by a single grain size.

- This capability was not considered in this analysis.

- Litpack capabilities include only one type of boundary condition (i.e., fixed shoreline angle). This was noted as a key feature driving differences in model results.

- Evaluation of software packages by a new user:

- Overall, GenCade was somewhat easier to learn than Unibest and Litpack for these test cases. Familiarity with other USACE modeling systems may have benefited GenCade in this evaluation.

- It was possible to review provided documentation and run successful demonstrations in fewer than 8 hours for all three models.

- Documentation was found to be approximately equal in terms of completeness and understandability from the perspective of a new user.

- The exception was that Litpack takes the extra step to integrate model documentation into the GUI. The Help function has model documentation broken down by the different steps/buttons in the GUI, making it easy to find documentation related to each feature. 
○ The tree approach to model setup used in Unibest made it easier to keep track of all the model inputs required and made it easier to remember how to set up and execute the model. Both Litpack and GenCade require the user to search through file drop-down menus to set up and execute the model, making it more difficult for the less-frequent user to remain fluent.

ACKNOWLEDGMENTS: This comparison of models was funded by the Coastal Inlets Research Program (CIRP), a Navigation Research and Development Program within USACE responsible for development of the GenCade modeling system. Although CIRP is obviously biased towards GenCade, an engineer new to shoreline change modeling (Kimberly Townsend), not associated with CIRP, was selected to complete this analysis to attempt to provide an unbiased review of these modeling systems.

POINTS OF CONTACT: For additional information, contact Kimberly Townsend (409-7663854), Kimberly.E.Townsend@usace.army.mil; Robert Thomas (409-766-3975), Robert.C.Thomas@usace.army.mil; Ashley Frey (601-634-2006),Ashley.E.Frey@usace.army.mil; and/or the CIRP Program Manager, Dr. Julie Rosati (202-761-1850), Julie.D.Rosati@, usace.army.mil. This technical note should be cited as follows:

Townsend, K. E., R. C. Thomas, and A. E. Frey. 2014. Shoreline change modeling using one-line models: Application and comparison of GenCade, Unibest, and Litpak. ERDC/CHL CHETN-IV-102. Vicksburg, MS: U.S. Army Engineer Research and Development Center.

\section{REFERENCES}

Delft Hydraulics Institute (DHI). 2009. LITPACK: An integrated modeling system for littoral processes and coastline kinetics (short introduction and tutorial). Published by MIKE by DHI.

Deltares. 2011. UNIBEST-CL+ Manual: Manual for version 7.1 of the shoreline model UNIBEST-CL+. Draft 2001.

Frey, A., K. Connell, H. Hanson, M. Larson, R. Thomas, S. Munger, and A. Zundel. 2012. GenCade version 1 model theory and user's guide. ERDC/CHL TR-12-25. Vicksburg, MS: U.S. Army Engineer Research and Development Center.

Thomas, R. C., and A. E. Frey. 2013. Shoreline change modeling using one-line models: General model comparison and literature review. ERDC/CHL CHETN-II-55. Vicksburg, MS: U.S. Army Engineer Research and Development Center.

NOTE: The contents of this technical note are not to be used for advertising, publication, or promotional purposes. Citation of trade names does not constitute an official endorsement or approval of the use of such products. 